\title{
A HAND CAMPIMETER FOR THE CONFRONTATION TEST
}

BY

George Mackay, M.D., F.R.C.S.E.

\section{EDINBURGH}

THIS campimeter has been designed to provide a simple method of measuring the approximate extent of the field of vision as now required by the standard of visual deficiency set up by the Department of Health in Scotland (and recommended for adoption in England) in connection with the administration of the Blind Persons' Act (1920).*

It affords a means of estimating the field for hand movements with more precision than is possible by a mere guess on the part of the examiner when moving his hand through uncharted air. If a finer test object than a hand be employed, the measurement can, of course, be made more accurate. But for the visually defective who are applying for blind persons' benefits, refined tests are rarely necessary, or if required-for instance, for scotomata-can be made with an ordinary screen campimeter or perimeter.

The apparatus consists of three concentric circular rings of wire. The innermost when held in a vertical plane at a distance of approximately twenty inches from the patient's face delimits a field of $10^{\circ}$. The outermost ring corresponds to a field of $20^{\circ}$. The intermediate circle indicates a field extending to $15^{\circ}$ in all directions from the line of fixation. The radiating wires not only act as bracing staves but indicate the vertical and horizontal division of the field into half fields, quadrants and octants. The innermost ring is painted white to facilitate its recognition by a partially blind person. The other two rings are painted black and connected by a wooden handle which supports the whole frame.

A single cord twenty inches (half a metre) long attached to the handle and held fully extended by the patient with the free end resting on his cheek may be used to give the correct distance which should be maintained between the plane of his face and that of the frame throughout the test. But if the cord be suitably lengthened and made into a loop it can be passed behind the patient's neck and the proper distance is secured by the examiner drawing the frame towards himself sufficiently to keep the doubled cord taut while the patient remains impassive. A bead on each limb of the loop indicates the twenty inch measure and when the cord is in

* See Appendix I of the Joint Memorandum issued by the Department of Health for Scotland and the Scottish Education Department on October 22, 1931, published by H.M. Stationery Office, price $2 d$. 
position the beads should be approximately in the same vertical plane as the patient's eyes.

Each eye can be tested separately, if desired, in the ordinary way employed in the confrontation test, one eye being covered, and the patient's right eye fixing the examiner's left eye or the patient's

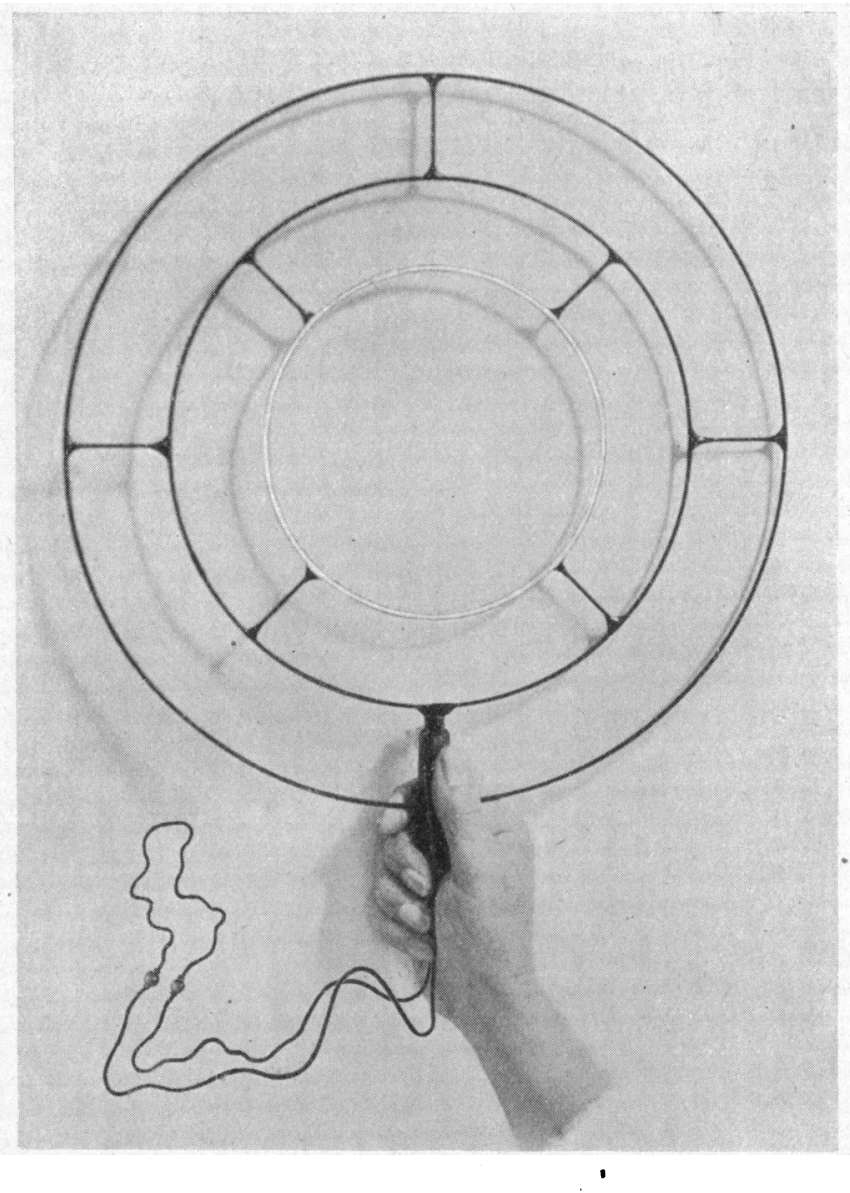

left eye fixing the examiner's right eye. But the actual requirement for the certification of blindness is the ascertainment of the total field with both eyes open. For that purpose the patient is requested to look through the centre of the white ring to the root of the examiner's nose, with both eyes open, if both are present.

This campimeter was exhibited at the Edinburgh meeting of the Ophthal. Soc. U.K. in May, 1932. It can be supplied by Theodore Hamblin, Ltd., 15, Wigmore Street, Cavendish Square, London, W.1. 